acids, suggesting the presence of two, or the equivalent of two, double bonds.

From the iodine value $(98 \cdot 2)$ and diene value $(40 \cdot 3)$, it may be inferred that these double bonds are probably conjugated, although the ultra-violet absorption spectrum does not show any band in the region 2200-3200 A. The infra-red curve, however, gives clear indication of a cyclopropane ring at $9.96 \mu$ and a double bond $(\mathrm{C}=\mathrm{C})$ at $6 \cdot 09 \mu$ on the shoulder of the strong carbonyl band at $5.9 \mu$.

The cyclopropane ring exhibits typical unsaturation towards many specific additive reagents, as demonstrated by Kohler and Conant ${ }^{4}$. Therefore, the cyclapropane ring in sterculic acid may form a 'conjugated system' with the double bond, resulting in structure (II).

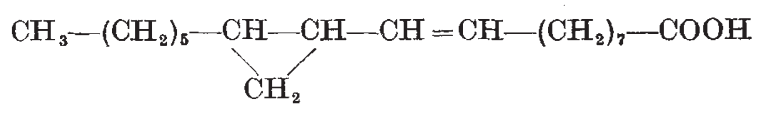

Reduction and oxidation products obtained by various investigators ${ }^{1,8}$ and also by us find ready explanation with this structure.

Further, the synthesis of compound I has been effected from stearolic acid by the action of diazomethane. This synthetic product gives an infra-red curve which is different from that of sterculic acid, thereby conclusively showing that the structure (I) is not correct.

The details of this work will be published elsewhere.

$$
\begin{aligned}
& \text { J. P. VERMA } \\
& \text { BHot NATH } \\
& \text { J. S. AgGaRWAL }
\end{aligned}
$$

National Chemical Laboratory of India,

$$
\text { Poona } 8 .
$$

Sept. 3.

${ }^{1}$ Hilditch, Meara and Zaky, J. Soc. Chem. Indust., 60, 198T (1941). ${ }^{3}$ Steger and Van Loon, Fette u. Seifen, 50, 305 (1943).

3 Nunn, J. Chem. Soc., 313 (1952).

4 Kohler and Conant, J. Amer. Chem. Soc., 39, 1404 (1917).

\section{Separation of Saponins by Paper Chromatography}

IN the course of a study on the composition of saponins from Indian raw materials, difficulties were encountered in the complete separation of the glycosides in pure form by chemical means. The usual method of repeated precipitation with solvents is not dependable and does not ensure the chemical purity of the separated products, the more so because many of the saponins are hygroscopic.

A convenient method of separation has now been developed by paper partition chromatography. The spray reagent used was sodium periodate in alkaline permanganate solution, recently reported by Lemieux and Bauer ${ }^{1}$ for the detection of carbohydrates; this has been found to be satisfactory in the case of saponins, giving permanent brown spots against a white background.

Qualitative characterization of the fairly pure saponins ${ }^{2}$, isolated in this laboratory, was carried out on Whatman No. 1 filter-paper by the ascending method $^{3}$ with the system $n$-butanol-acetic acid water $(4: 1: 5)$ for $10-24 \mathrm{hr}$, and the dried papers were sprayed with a freshly prepared solution of sodium meta-periodate in alkaline potassium per-

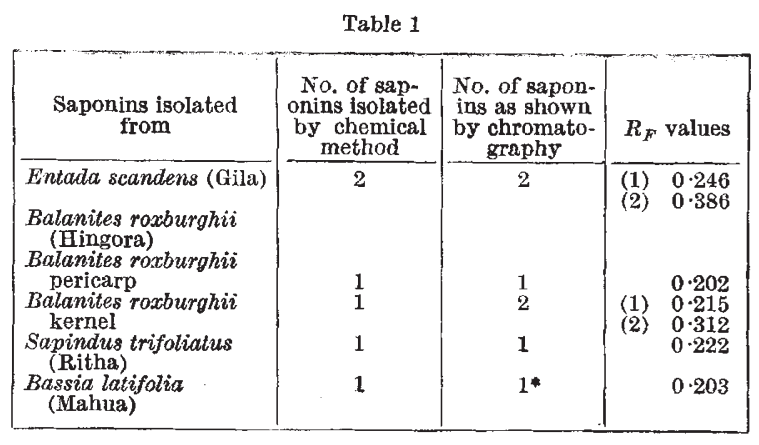

* One distinct spot and two indistinct spots on the strip

manganate solution. The papers were left for an appropriate time $(5-6 \mathrm{~min}$.) before they were washed with running water, when distinct brown spots of saponins appeared against the almost white background of the paper. On drying, these spots remained unchanged for an indefinite period.

The $R_{F}$ values found for the respective saponins are shown in Table 1. By employing this method, it has been possible to show that the saponins, purified by the usual chemical procedure, are in some cases actually composed of more than one saponin. Other solvent systems are being examined. Details will be published elsewhere in due course.

National Chemical Laboratory of India,

N. L. DUTTA

Poona, 8.

Sept. 10.

${ }^{1}$ Lemieux, R. U., and Bauer, H. F., Anal. Chem., 26, 920 (1954). "Dutta, N. L., Curr. Sci., 23,222 (1954); Pharm: Acta Helv., [29,
$260(1954)] ;$ J. Sci. and' Ind. Res., India, [138, 672 (1954)]. ${ }^{3}$ Partridge, Biochem. J. 42, 238 (1948).

\section{Techniques for labelling Trees with Radioactive Phosphorus}

INSECxs feeding on plants in nutrient culture solution have been labelled with tracer-levels of radioactive isotopes in studies of insect feeding-habits ${ }^{1}$ and insecticidal action ${ }^{2}$. Such insects have also been released in the field for population studies ${ }^{3}$, and others fed on labelled artificial diets have been used in the study of insect metabolism4.

To investigate the movement of the mealybug vectors of swollen shoot disease of cacao, techniques were studied for obtaining radioactive trees for the subsequent labelling of insects at their feeding sites under field conditions. The artificial release of labelled insects in the field is unsatisfactory for such investigations.

By the first method a panel of bark was removed from the stem of Abutilon sp. and $1.5 \mathrm{mc}$. of phosphorus-32 in a volume of $3 \mathrm{ml}$. held in a 'Plasticine' cup was introduced laterally through the severed conducting vessels. After $24 \mathrm{hr}$., leaves $4 \mathrm{ft}$. above the area of introduction provided 300 counts $/ \mathrm{min}$./sq. cm., and after $48 \mathrm{hr}$. nymphs of Dysdercus sp. feeding $5 \mathrm{ft}$. above the place of injection provided 12-346 counts/min. This technique has been used successfully in translocation studies with dyes ${ }^{5}$, and the resulting mechanical damage to the tree is small. The amount of radiophosphorus translocated is uncertain because of the high residual activity on the 'Plasticine' cup. With high levels of activity, this technique presents some radiation hazard in the field. Fig. I shows that 